\title{
In vitro fertilisation in Hong Kong: the situation in 2019
}

\author{
MW Lui, William SB Yeung, PC Ho, Ernest HY Ng *
}

This article was published on 4 Dec 2019 at www.hkmj.org.

\section{A B S T R A C T}

The popularity of in vitro fertilisation has continuously increased throughout the past 40 years owing to an increased incidence of infertility and delayed planning for pregnancy. The aim of this paper is to review the current situation of in vitro fertilisation in Hong Kong. In Hong Kong, in 2018, 7995 women underwent 5055 fresh and 5050 frozenthawed embryo in vitro fertilisation cycles, resulting in an ongoing pregnancy rate of $33.7 \%$ per transfer. However, in vitro fertilisation is associated with several problems, including a high rate of multiple pregnancies and risks associated with cross-border reproductive care. Single embryo transfer is a simple strategy to reduce multiple pregnancies without compromising the cumulative live birth rate.

\section{Hong Kong Med J 2019;25:468-72}

https://doi.org/10.12809/hkmj198057

MW Lui, MB, BS

WSB Yeung, PhD

$P C H O, M B, B S, M D$

EHY Ng *, MB, BS, MD

Department of Obstetrics and Gynaecology, The University of Hong Kong, Pokfulam, Hong Kong

* Corresponding author: nghye@hku.hk

\section{Introduction}

The incidence of infertility has increased in recent decades, and women are more often delaying marriage and pregnancy. The mean age at which women deliver their first baby has increased from 27.9 years in 1995 to 30.5 years in $2017 .{ }^{1}$ Owing to the natural decline in fertility with age, more and more couples seek help to conceive through IVF. The number of IVF cycles performed in Europe increased from 203225 cycles in 1997 to 776556 in 2014, with 170163 babies born. ${ }^{2}$ A similar trend has been observed worldwide. ${ }^{3}$ The aim of this paper is to review the current situation of IVF in 2019.

\section{History of the in vitro fertilisation process}

Last year in 2018, the first "test tube" baby Louise Brown celebrated her 40th birthday. In vitro fertilisation was pioneered by Patrick Steptoe and Robert Edwards. They first obtained an oocyte in a natural cycle using a laparoscope. After it was fertilised in the laboratory, they transferred the embryo back to the donor's uterus. The techniques of IVF have progressed rapidly since then. The success rate has also greatly increased from lower than $1 \%$ per cycle to around $35 \%$ per cycle. The success rate has increased owing to several factors, including ovarian stimulation, assisted fertilisation using intracytoplasmic sperm insemination, improvements in culture conditions, and more advanced embryo transfer techniques.

Modern IVF cycles include ovarian stimulation, oocyte retrieval, fertilisation and culture in vitro, and embryo transfer to the uterus. Ovarian stimulation involves administration of gonadotropin, coupled with suppression of endogenous gonadotropin release by either gonadotropin-releasing hormone (GnRH) agonist or antagonist. The superphysiological doses of gonadotropins enhance growth of multiple follicles, in contrast to the development of a single follicle in a natural cycle. The use of GnRH agonist or antagonist reduces the risk of premature ovulation. Women undergoing ovarian stimulation need close monitoring, with pelvic scanning to determine the number and size of the follicles and hormonal tests to measure the serum oestradiol level. When the leading follicles reach $>17$ to $18 \mathrm{~mm}$, human chorionic gonadotropin is usually given to the patient to trigger the final maturation of the oocytes.

At 36 to 38 hours after the trigger, oocyte retrieval is typically performed through the transvaginal route under ultrasound guidance. An aspiration needle is used to puncture through the vagina to aspirate the follicular fluid with the oocytes and the follicles are aspirated till complete collapse of the follicles. Oocyte retrieval involves a small risk of bleeding, infection, pain, and risk of injury to visceral organs.

In vitro fertilisation refers to the overnight co-culture of oocytes with sperm. For couples with severe male factor infertility or fertilisation problems in previous IVF cycles, intracytoplasmic sperm insemination involving injection of a single sperm into an oocyte is advised. ${ }^{4}$ The fertilised embryo is transferred back to the uterine cavity either at cleavage (Day 2 or 3 ) or blastocyst stage (Day 5 ). 
Surplus high quality fertilised embryos can be frozen at the cleavage or blastocyst stage for subsequent transfer by slow freezing or more commonly by vitrification, which involves rapid freezing in liquid nitrogen. Vitrification enables a rapid transition of the liquid form of water to a "glass" status, which avoids crystallisation that can damage the cells.

In vitro fertilisation is not without risks, even in healthy couples. The most common complications of IVF are multiple pregnancy followed by ovarian hyperstimulation syndrome, which can lead to ascites, pleural effusion, venous thromboembolism, or even death. Although severe ovarian hyperstimulation syndrome has a low incidence, it can be potentially life-threatening and is avoidable. In cycles using $\mathrm{GnRH}$ antagonists to prevent premature ovulation, agonist can be used instead of human chorionic gonadotropin as a trigger for oocyte final maturation in order to lower the risk of ovarian hyperstimulation syndrome. ${ }^{2,5}$

Overall, the success of IVF greatly depends on the woman's age. As shown by the latest data by ESHRE (European Society of Human Reproduction and Embryology), ${ }^{2}$ in 2014, live birth rates after fresh transfer IVF in women aged $<35,35$ to 39 , and $\geq 40$ years were $23.8 \%, 18.8 \%$, and $8.1 \%$, respectively. For women aged $<30$ years, the cumulative live birth rate after completion of a cycle can be nearly $70 \%$, compared with $17.3 \%$ in women aged $\geq 40$ years. ${ }^{4}$

\section{In vitro fertilisation in Hong Kong}

\section{History and development}

In Hong Kong, IVF programmes were initiated in the Department of Obstetrics and Gynaecology, The Chinese University of Hong Kong in December 1984, in the Hong Kong Sanatorium \& Hospital in January 1986, and in the Department of Obstetrics and Gynaecology, The University of Hong Kong in July 1986. ${ }^{7}$ The Hong Kong Sanatorium \& Hospital

\section{香港體外受孕2019的現況 \\ 雷雯華、楊樹標、何柏松、吳鴻裕}

過去 40 年, 由於不孕的發生率增加和延遲生育計劃, 體外受精日趨普 及。本文回顧香港體外受精的現況。在香港, 2018年共有7995名婦女 接受 5055 例鮮胚體外受精和 5050 例凍肧體外受精, 導致每次體外受精 的持續妊娠率達 $33.7 \%$ 。然而, 體外受精與若干問題相關, 包括高比 例多胎妊娠和與跨境生育保健相關的風險。單胚胎移植是減低多胎妊 娠而不損害累計活產率的簡易策略。

programme achieved the first successful IVF pregnancy and delivery in Hong Kong.?

By August 1987, 522 IVF cycles had been initiated in Hong Kong and the overall clinical pregnancy rate was $5.2 \%$ per cycle initiated. ${ }^{6}$ From January 1992 to December 1993, 912 IVF cycles, 158 cycles of gamete intrafallopian transfer, 87 cycles of zygote intrafallopian transfer, and 233 cycles of frozen-thawed embryo transfer (FET) were initiated, with delivery rates per cycle started of $8.4 \%, 29.1 \%$, $13.8 \%$, and $11.2 \%$, respectively. ${ }^{8}$

More recently, according to the Council on Human Reproductive Technology (HRT Council) Annual Report, ${ }^{9}$ the number of women undergoing IVF increased from 2415 in 2009 to 7995 in 2018, with the number of fresh and FET IVF cycles increasing from 2768 to 10105 over the same period (Table 1). The ongoing pregnancy rate per transfer increased slightly from $29.9 \%$ in 2009 to $32.8 \%$ in 2015 and remained steady in 2015 to 2018 (Table 2). The ongoing pregnancy rate per transfer was $33.7 \%$ in 2018. However, there was no significant increase in live birth rates throughout the years. Both ongoing and live birth rates are markedly reduced in women aged $\geq 41$ years.

TABLE I. In vitro fertilisation cycles from 2009 to 2018 in Hong Kong, data from the Council on Human Reproductive Technology Annual Report ${ }^{\prime \prime}$

\begin{tabular}{|c|c|c|c|c|c|c|c|c|c|c|}
\hline & 2009 & 2010 & 2011 & 2012 & 2013 & 2014 & 2015 & 2016 & 2017 & 2018 \\
\hline No. of women & 2415 & 5172 & 6426 & 7082 & 6712 & 8392 & 7997 & 8073 & 7463 & 7995 \\
\hline No. of cycles & 2768 & 6451 & 8039 & 8751 & 8158 & 10498 & 9859 & 9999 & 9586 & 10105 \\
\hline No. of fresh cycles & 1783 & 4016 & 4924 & 5189 & 4860 & 6003 & 5320 & 5136 & 5099 & 5055 \\
\hline No. of FET cycles & 985 & 2435 & 3115 & 3562 & 3298 & 4495 & 4539 & 4863 & 4487 & 5050 \\
\hline Ongoing PR per transfer & $29.9 \%$ & $29.2 \%$ & $27.5 \%$ & $29.3 \%$ & $30.5 \%$ & $31.6 \%$ & $32.8 \%$ & $33.8 \%$ & $33.7 \%$ & $33.7 \%$ \\
\hline Live birth rate per transfer & $25.7 \%$ & $23.5 \%$ & $22.5 \%$ & $23.5 \%$ & $24.5 \%$ & $26.3 \%$ & $26.1 \%$ & $28.2 \%$ & $27.8 \%$ & NA \\
\hline No. of embryos replaced per transfer & 2.24 & 2.30 & 2.19 & 2.06 & 1.95 & 1.83 & 1.76 & 1.63 & 1.56 & 1.44 \\
\hline $\begin{array}{l}\text { Multiple pregnancy rate per ongoing } \\
\text { pregnancy* }\end{array}$ & $23.7 \%$ & $19.3 \%$ & $20.6 \%$ & $20.1 \%$ & $20.1 \%$ & $18.9 \%$ & $15.7 \%$ & $17.2 \%$ & $15.2 \%$ & NA \\
\hline
\end{tabular}

Abbreviations: FET = frozen-thawed embryo transfer; $\mathrm{NA}=$ not available; $\mathrm{PR}=$ pregnancy rate

* Multiple pregnancy rate per ongoing pregnancy, which is different from multiple pregnancy rate per treatment cycle in the Council on Human Reproductive Technology Annual Reports 
TABLE 2. Ongoing pregnancy rate and live birth rate of both fresh and frozen cycles according to age for women who underwent in vitro fertilisation in $2017^{11}$

\begin{tabular}{lccc}
\hline $\begin{array}{l}\text { Age } \\
\text { (years) }\end{array}$ & $\begin{array}{c}\text { No. of fresh } \\
\text { and frozen } \\
\text { cycles }\end{array}$ & $\begin{array}{c}\text { Ongoing } \\
\text { pregnancy rate } \\
\text { per transfer }\end{array}$ & $\begin{array}{c}\text { Live birth } \\
\text { rate per } \\
\text { transfer }\end{array}$ \\
\hline$\leq 30$ & 424 & $46.2 \%$ & $40.3 \%$ \\
$31-35$ & 1914 & $42.4 \%$ & $36.8 \%$ \\
$36-40$ & 2663 & $33.5 \%$ & $27.3 \%$ \\
$\geq 41$ & 1180 & $15.8 \%$ & $10.7 \%$ \\
\hline
\end{tabular}

The number of embryos transferred has reduced gradually over the years, though double embryo transfer still is the most common. The single embryo transfer rate has increased from 12.9\% (321 cycles) in 2009 to $49.2 \%$ (3043 cycles) in 2017. As a result, the multiple pregnancy rate per ongoing pregnancy has decreased, but remained high at $15.2 \%$ in 2017.

\section{Regulation of assisted reproduction}

Assisted reproduction in Hong Kong is regulated by the Human Reproductive Technology Ordinance (Cap. 561). ${ }^{10}$ Centres that provide IVF must obtain a treatment licence from the HRT Council. At the time of writing, there are 18 licensed treatment centres in Hong Kong and of these, 13 provide IVF. Of these 13 treatment centres, 10 are in the private sector and three are in the public sector. ${ }^{11}$

As stated in the HRT Council Code of Practice, ${ }^{6}$ in Hong Kong, IVF can be provided only to legally married couples in monogamous relationship. The maximum number of embryos that can be transferred to the woman is three per cycle. Frozen embryos can be stored for up to 10 years from the day of freezing, and gametes can be stored until the patient is aged 55 years. All IVF data must be documented clearly and reported promptly and accurately to the HRT Council. Commercial oocyte donation is not allowed in Hong Kong. ${ }^{11}$ No payment to the oocyte donor is allowed apart from reimbursing the loss of earnings and the expenses, such as transportation and appointment fee. Sex selection, unless medically indicated, is also prohibited in Hong Kong. Although surrogacy is legal in Hong Kong, none of the centres in Hong Kong has a licence for surrogacy arrangements, and surrogacy agreements have been found to be unenforceable under the law. ${ }^{11}$

\section{Public in vitro fertilisation service}

Currently, IVF service is provided in three public hospitals in Hong Kong: Kwong Wah Hospital, Prince of Wales Hospital, and Queen Mary Hospital. Eligible couples can receive partial subsidy funding from the Hong Kong Hospital Authority for up to three IVF cycles. The number of publicly funded cycles has increased to around 1000 cycles in total in 2018. The criteria for funded IVF cycles include women who are permanent Hong Kong residents, aged $<40$ years, and with no biological children. The waiting time for IVF in public hospitals in Hong Kong is up to 3 years. The provision of IVF in public hospitals is not entirely free of charge. Couples pay approximately $\mathrm{HK} \$ 20000$ for all medication, procedures, and embryo storage for up to three cycles, but this is lower than the HK\$80000 to HK $\$ 100000$ required for just one IVF cycle in the private sector.

\section{Recent in vitro fertilisation technology developments}

Chromosome aneuploidy

Chromosome aneuploidy is an error in cell division that results in the "daughter" cells having the wrong number of chromosomes. Chromosome aneuploidy is a major reason for failure of conception, pregnancy loss, and congenital anomalies following both natural conception and IVF pregnancies and its prevalence increases exponentially with maternal age. The need to assess embryo quality and select those with the highest potential for implantation on the basis of morphology has led to preimplantation genetic testing for aneuploidy (PGT-A). ${ }^{9}$ This involves biopsy of a few cells from an embryo at the blastocyst stage and assessment of the comprehensive chromosome copy numbers. Although PGT-A cannot create a healthy embryo or improve the health of an embryo, it can provide an accurate method of selecting of embryos with a normal number of chromosomes for transfer. This in turn has the potential to increase the chance of having a healthy live birth per each transfer and to reduce the risk of miscarriage or abnormal fetus caused by an abnormal number of chromosomes. ${ }^{12}$ However, the potential damage of trophectoderm biopsy on the developing embryos remains unknown. In addition, the concordance of trophectoderm biopsy and blastocyst is questionable especially in those with segmental aneuploidy ${ }^{13}$ and mosaicism. ${ }^{14}$ Gene editing may provide a new perspective in future, but there is still a long way ahead. Gene editing technologies are immature and imprecise, and involve unknown long-term risks.

\section{Oocyte freezing}

Oocyte freezing by vitrification is no longer considered to be experimental and is offered to women who desire preservation of their fertility potential before chemotherapy or radiotherapy for cancer treatment. In Hong Kong, the indication of oocyte freezing has been extended to single women who wish to delay parenthood for education or career purposes. In general, fertility preservation for cancer patients is underutilised, partly owing to 
lack of funding in the public sector and inadequate information for patients. Fertility preservation for cancer patients requires a close cooperation between fertility specialists, oncologists, paediatricians, and surgeons. Oocyte or embryo freezing provides more promising results in fertility preservation, but it involves a delay of treatment for at least 2 weeks and it is possible only in postpubertal women. Owing to the lack of funding, patients often need to pay for their own treatment.

\section{Problems facing in vitro fertilisation service in Hong Kong} Multiple pregnancy

There is an international goal aiming to reduce the incidence of multiple pregnancy as a result of IVF to $<10 \%$. Multiple pregnancies after IVF create a huge burden on the healthcare system. The chance of multiple pregnancy increases exponentially with the number of embryos transferred. Multiple pregnancies are associated with high risk of prematurity, low birth rate, and tremendous support from neonatal intensive care unit. It has been estimated that one premature baby at 29 weeks can cost up to US\$122000 and prematurity cost a total of US $\$ 4567$ billion in United Kingdom in 2006. ${ }^{15}$ Owing to improvements in embryo culture and cryopreservation techniques, with the use of vitrification, the cumulative pregnancy rate is similar in single or double embryo transfer. ${ }^{16}$ In Kwong Wah Hospital and Queen Mary Hospital, women can have only one embryo transferred at a time unless they are aged $\geq 38$ years, have failed two IVF cycles, and have had no live births. Although single embryo transfer results in a slightly longer interval to pregnancy, it can significantly lower the multiple pregnancy rate to $<2 \%{ }^{16}$

\section{Cross-border reproductive care}

The reasons for Hong Kong residents seeking crossborder reproductive care are multifactorial. Reasons may include the long waiting times for publicly funded IVF, the high cost of private IVF, lack of oocyte donors, and ineligibility for IVF in Hong Kong. Those ineligible for IVF in Hong Kong include unmarried couples, same-sex couples, and those seeking IVF for surrogacy, sex selection, or social reasons. Women seeking IVF overseas face risks including lack of regulations in some centres and lack of medical care or insurance coverage in case of complications.

\section{Other problems}

Other problems include the risks of ovarian hyperstimulation syndrome, the high cost of IVF, and difficulty in getting gamete and embryo donation.

\section{Conclusion}

In vitro fertilisation provides hope for infertile couples. However, there are many unresolved issues, especially the high rate of multiple pregnancies and potential risks associated with cross-border reproductive care.

\section{Author contributions}

All authors had full access to the data, contributed to the study, approved the final version for publication, and take responsibility for its accuracy and integrity.

Concept or design: EHY Ng.

Acquisition of data: MW Lui.

Analysis or interpretation of data: MW Lui.

Drafting of the article: MW Lui.

Critical revision for important intellectual content: WSB Yeung, PC Ho, EHY Ng.

\section{Conflicts of interest}

All authors have disclosed no conflicts of interest.

\section{Funding/support}

This research received no specific grant from any funding agency in the public, commercial, or not-for-profit.

\section{References}

1. Organisation for Economic Co-operation and Development. OECD Family Database. SF2.3.B. Age of mothers at childbirth and age-specific fertility. Available from: http://www.oecd.org/els/family/database.htm. Accessed 26 Jul 2019.

2. De Geyter C, Calhaz-Jorge C, Kupka MS, et al. ART in Europe, 2014: results generated from European registries by ESHRE: The European IVF-monitoring Consortium (EIM) for the European Society of Human Reproduction and Embryology (ESHRE). Hum Reprod 2018;33:1586-601.

3. Chambers GM, Wand H, Macaldowie A, Chapman MG, Farquhar CM, Bowman M, Molloy, D, Ledger W. Population trends and live birth rates associated with common ART treatment strategies. Hum Reprod 2016;31:2632-41.

4. Babayev SN, Park CW, Bukulmez O. Intracytoplasmic sperm injection indications: how rigorous? Semin Reprod Med 2014;32:283-90.

5. McLernon DJ, Maheshwari A, Lee AJ, Bhattacharya S. Cumulative live birth rates after one or more complete cycles of IVF: a population-based study of linked cycle data from 178,898 women. Hum Reprod 2016;31:572-81.

6. Council on Human Reproductive Technology. Code of Practice on Reproductive Technology and Embryo Research. January 2013. Available from: https://www.chrt. org.hk/english/service/service_cod.html. Accessed 26 Jul 2019.

7. Mao KR, Loong EP, Lee HC, et al. Current status of in-vitro fertilization (IVF) in Hong Kong. J Hong Kong Med Assoc 1987;39:144-6.

8. Hong Kong IVF Study Group. Assisted reproduction in Hong Kong: status in the 1990s. Hong Kong Med J 1996;2:253-6.

9. Lehmann L, El-Haddad A, Barr RD. Global approach to 
hematologic malignancies. Hematol Oncol Clin North Am 2016;30:417-32.

10. Cap. 561 Human reproductive technology ordinance 2000 (Hong Kong SAR). Available from: https://www. elegislation.gov.hk/hk/cap561. Accessed 26 Jul 2019.

11. Council on Human Reproductive Technology. Available from: https://www.chrt.org.hk/. Accessed 26 Jul 2019.

12. Maxwell SM, Grifo JA. Should every embryo undergo preimplantation genetic testing for aneuploidy? A review of the modern approach to in vitro fertilization. Best Pract Res Clin Obstet Gynaecol 2018;53:38-47.

13. Victor AR, Griffin DK, Brake AJ, et al. Assessment of aneuploidy concordance between clinical trophectoderm biopsy and blastocyst. Hum Reprod 2019;34:181-92.

14. Capalbo A, Ubaldi FM, Rienzi L, Scott R, Treff N. Detecting mosaicism in trophectoderm biopsies: current challenges and future possibilities. Hum Reprod 2017;32:492-8.

15. Saha S, Gerdtham UG. Cost of illness studies on reproductive, maternal, newborn, and child health: a systematic literature review. Health Econ Rev 2013;3:24.

16. Pandian Z, Marjoribanks J, Ozturk O, Serour G, Bhattacharya S. Number of embryos for transfer following in vitro fertilisation or intra-cytoplasmic sperm injection. Cochrane Database Syst Rev 2013;(7):CD003416. 